\title{
\begin{tabular}{l|l} 
Mibraries & DSpace@MIT
\end{tabular}
}

\author{
MIT Open Access Articles
}

\section{An Origami-Inspired Design of a Thermal Mixing Element Within a Concentrated Solar Power System}

The MIT Faculty has made this article openly available. Please share how this access benefits you. Your story matters.

Citation: Hamer, Tyler T., Lei Zhou, David L. Trumper, Alexander H. Slocum, and Nicolas Calvet. "An Origami-Inspired Design of a Thermal Mixing Element Within a Concentrated Solar Power System." ASME 2017 International Design Engineering Technical Conferences and Computers and Information in Engineering Conference, 6-9 August, 2017, Cleveland, Ohio, ASME, 2017. (C) 2017 ASME

As Published: http://dx.doi.org/10.1115/DETC2017-68360

Publisher: ASME International

Persistent URL: http://hdl.handle.net/1721.1/120984

Version: Final published version: final published article, as it appeared in a journal, conference proceedings, or other formally published context

Terms of Use: Article is made available in accordance with the publisher's policy and may be subject to US copyright law. Please refer to the publisher's site for terms of use. 


\section{AN ORIGAMI-INSPIRED DESIGN OF A THERMAL MIXING ELEMENT WITHIN A CONCENTRATED SOLAR POWER SYSTEM}

\author{
Tyler T. Hamer \\ Massachusetts Institute of Technology \\ Cambridge, Massachusetts 02139 \\ tyhammer@mit.edu
}

\author{
Lei Zhou \\ Massachusetts Institute of Technology \\ Cambridge, Massachusetts 02139 \\ leizhou@mit.edu
}

\author{
David L. Trumper \\ Massachusetts Institute of Technology \\ Cambridge, Massachusetts 02139 \\ trumper@mit.edu
}

\author{
Alexander H. Slocum \\ Massachusetts Institute of Technology \\ Cambridge, Massachusetts 02139 \\ slocum@mit.edu
}

\author{
Nicolas Calvet \\ Masdar Institute of Science and Technology \\ Abu Dhabi, United Arab Emirates \\ ncalvet@masdar.ac.ae
}

\begin{abstract}
A Concentrated Solar Power on Demand (CSPonD) system heats a tank of molten salt with sunlight, storing the sun's energy thermally and generating electricity when needed using a heat exchanger. To prevent the heated salt from forming thermal gradients (reducing the heat exchanger's efficiency) or overheating (and becoming corrosive), a thermal mixing element mixes the heated salt both axially and radially. Since the mixing element can only move axially within the tank, it contains internal, radial channels to induce radial flow of the salt. These channels are constructed from tabbed wall-components, whose tabs seat into and extend past slots in the top-and bottom-plates of the mixing element. The top-and bottom-plates are constructed from multiple panels with overlapping slots, allowing the panels to form the plates when the tabs are inserted. This interlocking design allows majority of the mixing element to be rapidly manufactured at a low cost from sheet metal and simplifies transportation. In situ, the assembled components fasten together by bending the overextending tabs, minimizing the number of fasteners needed.
\end{abstract}

\section{INTRODUCTION}

Origami, the Japanese art of paper folding, provides a methodology for constructing three-dimensional geometries from two-dimensional sheets. Designs inspired by this methodology can be found within many fields, such as packaging-andstorage, robotics, manufacturing, and structural engineering [1]. Despite use in different fields, several similarities exist between these origami-inspired designs. Origami-inspired designs can often be rapidly manufactured for a low cost. Within manufacturing, origami-inspired designs have been created since the late 50 's with the emergence of sheet metal. Designs made from sheet metal are easily and quickly cut using punching, nibbling, laser cutting, plasma cutting, and waterjet cutting, and then reshaped using press brake bending, deep drawing, and roll forming [2]. Further, multiple shaped sheet metal components can be combined if necessary, with techniques such as tab-and-slot construction and fastened together with techniques such as t-nut construction $[3,4]$ and deformation of tabs extending beyond slots $[5,6]$. In addition, many origami-inspired designs collapse into a compact state, allowing for easy transportation and storage, while utilizing self-locking and/or bent structures to increase rigidity in an expanded state [1]. These two properties have been used in the packing industry since the 1890 s with the National Biscuit Company using cartons to store their crackers [7] and are still found today from in products from cereal boxes to takeout containers. 

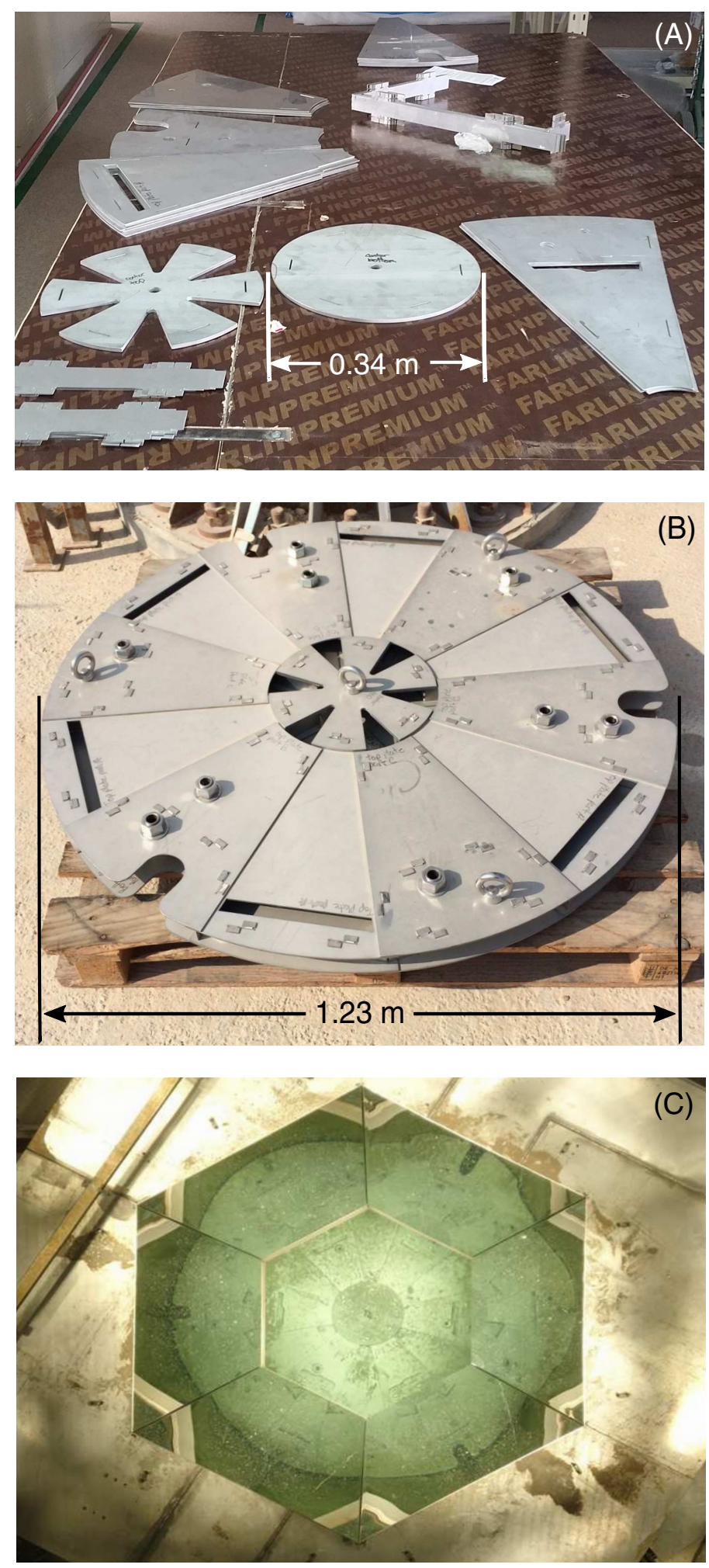

FIGURE 1: THERMAL MIXING ELEMENT (A) BEFOREAND (B) AFTER-ASSEMBLY AND (C) SUBMERGED IN NEAR-BOILING WATER IN THE MOLTEN SALT TANK.
This paper presents the design of a thermal mixing element within a Concentrated Solar Power on Demand (CSPonD) system that utilizes these advantages found in origami-inspired designs. The thermal mixing element is shown in Figure 1 beforeand after-assembly, and submerged in near-boiling water after installation in the molten salt tank. In particular, the mixing element is constructed from two-dimensional components cut using a waterjet. This allows the mixing element to be rapidly and cheaply manufactured and then easily transported in stacks to the CSPonD system. Additionally, several internal components are bent to increase the rigidity of the final assembly. In situ, the mixing element's components interlock using the tab-andslot construction technique to create the three-dimensional, 1.23 $\mathrm{m}$ diameter thermal mixing element with internal channels, able to promote both axial and radial mixing of molten salt. In this final assembly, the tabs extend past their respective slots, allowing them to be bent over to secure the interlocking components without the need for separate fasteners.

\section{BACKGROUND}

Concentrated Solar Power on Demand (CSPonD) systems are solar power systems that attempt to solve not only the issue of generating energy, but also storing it until needed $[8,9]$. Figure 2 shows the schematic for a beam-down CSPonD system at the Masdar Institute of Science and Technology in the United Arab Emirates [10]. Incoming sunlight is reflected off of heliostats (motorized mirrors tracking the sun) into tower-mounted beamdown mirrors. These beam-down mirrors redirect the sunlight into a final optical element (FOE), which focuses the sunlight into a tank of molten salt known as a receiver. The molten salt is separated into a hot region at $550^{\circ} \mathrm{C}$, in which the energy from the sunlight is stored, and a cold region at $280^{\circ} \mathrm{C}$, by a thermal insulating element.

To increase the stored energy, the insulating element moves downward. Due to a one-way valve on the heat exchanger, this forces the cold salt to flow through the annulus between the side of the insulating element and the wall of the tank into the hot region where it can be heated up. To generate electricity, the insulating element moves upward. Since the heat exchanger has a much lower fluid resistance than the annulus, majority of the hot salt flows into the heat exchanger where it can be used to generate steam and turn a steam turbine before returning to the cold region as cold salt.

Molten salt is used as the heat transfer fluid (HTF) as opposed to water for its high heat capacity, allowing for higher energy storage, and its wide range of operating temperatures, allowing for higher efficiency of the heat exchanger [8]. In particular, the Masdar CSPonD system uses solar salt, a binary sodium-potassium nitrate mixture (60-40 wt.\%) commonly used in central receiver Concentrated Solar Power (CSP) systems [11]. However, solar salt begins to decompose into a corrosive, danger- 


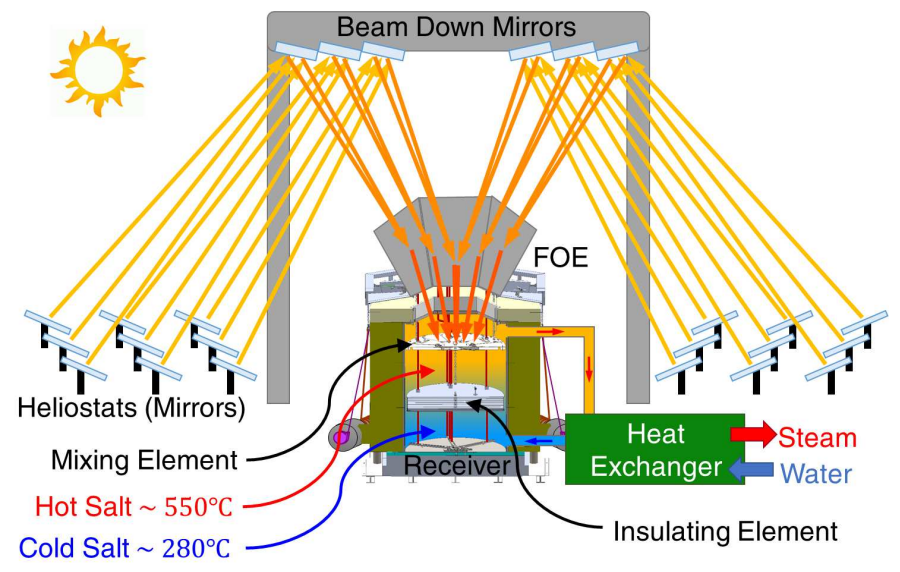

FIGURE 2: SCHEMATIC OF THE BEAM-DOWN CONCENTRATED SOLAR POWER ON DEMAND (CSPonD) SYSTEM AT THE MASDAR INSTITUTE INSTITUTE OF SCIENCE AND TECHNOLOGY IN THE UNITED ARAB EMIRATES.

ous substance above $600^{\circ} \mathrm{C}$ and solidifies at $222^{\circ} \mathrm{C}$, temperatures near the hot and cold region's operating temperatures [8]. Further, solar salt has high absorption within the solar spectrum, but poor thermal conductivity. This causes a strong thermal gradient to form within the hot region as only its upper layers are heated by the sunlight.

To reduce this thermal gradient and safeguard against upper layers of the hot region overheating, a thermal mixing element within the hot region moves up and down, inducing both axial and radial mixing of the hot region. Radial mixing is needed in addition to axial mixing as incoming sunlight is focused into the center of the tank by the FOE instead of being distributed across the top of the tank. To keep the hot region well mixed, the mixing element moves on a much shorter time scale than the insulating element. Simulations show that the insulating element takes roughly 50 minutes to travel from the top of the tank to the bottom of the tank when increasing the energy stored, while the mixing element is predicted to traverse up and down the entire tank in roughly two minutes, every ten minutes, when the insulating element is at the bottom of the tank.

The insulating and mixing elements are each actuated by three synchronized winches attached via chains. Since the chains can only support tension, not compression, the winches can only apply upward forces on their respective element. Upward forces from the winches' brakes keep each element in place when motion is not desired. To move an element upward, its winches' brakes disengage and its winches apply a lifting force, pulling the element upward. To move an element downward, its winches apply a torque to overcome their breaks and the weight of the element pulls itself downward.

\section{MIXING ELEMENT REQUIREMENTS}

To uniformly mix the hot region, the mixing element's motion must induce both axial and radial mixing of the salt. Axial mixing is simple to induce as the mixing element moves axially within the tank. As the mixing element moves, displaced salt flows axially through holes within the mixing element and through the annulus between the mixing element's side and the tank's walls. Radial mixing is more complicated to induce as the mixing element does not move radially. Instead, radial flow of the salt must also be induced by the axial motion of the mixing element. This can be done by directing the axial flow of the salt as it flows through holes in the mixing element. In particular, the holes within the mixing element can slant inward and outward radially or the holes can connect to internal channels which direct the flow inward and outward radially.

Since flow through the slanted holes or channels in the mixing element induces radial mixing, but flow through the annulus does not, majority of the salt should flow through the mixing element, not around it. For the majority of the salt to flow through the mixing element, the fluid resistance through the mixing element must be lower than the fluid resistance around it. For the fluid resistance around the mixing element to be high, the mixing element's diameter $(1.23 \mathrm{~m})$ must be close to the diameter of the tank $(1.25 \mathrm{~m})$. Coupling this requirement with the mixing element relying on its weight to move downward, the mixing element can easily be quite bulky.

Figure 3 shows the initial bulky designs of the mixing element. In Design A, metal pipes sandwiched between two large plates direct the salt flow radially. Theses pipes can be welded directly to the plates or attached using fasteners via shaft collars or base flanges. In Design B, two large plates with milled slots are fastened together to form channels that can direct the salt flow radially. In Design $\mathrm{C}$, thick, tabbed wall-components seat into two slotted, large plates to form channels that direct the salt flow radially. These wall-components can be secured with the t-nut construction technique or via tapped holes in the wallcomponents provided the wall-components are thick enough.

These designs are problematic in several ways. First, they are slow and difficult to manufacture. All three designs have large plates to increase the fluidic resistance of the annulus, which would require a large machine to cut. Further in Design $\mathrm{B}$, a large $\mathrm{CNC}$ mill is also needed to mill slots in the plates. Second, these designs are difficult and costly to transport. This is primarily due to the size and weight of the large plates in each design. However, if the pipes in Design A are fabricated and assembled before transportation, these pipes could also be another source. Third, these designs are slow and difficult to assemble due to the potentially large number of fasteners required. This is especially true for the t-nut assembled version of Design $\mathrm{C}$ as the t-nut construction technique works best on a small scale. The welded version of Design A appears as a promising way to simplify assembly, but welding is not readily available in situ. In- 
(A)

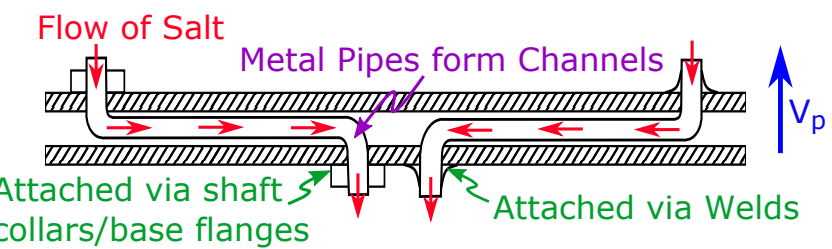

(B)

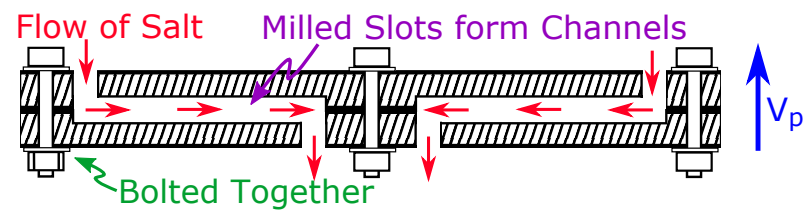

(C)

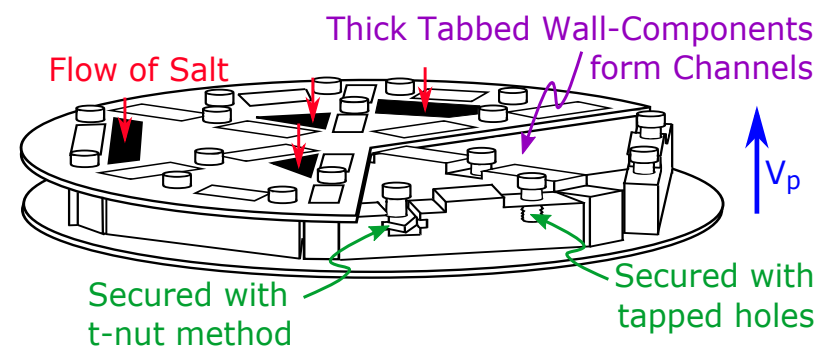

FIGURE 3: PRE-ORIGAMI-INSPIRED DESIGNS FOR THE THERMAL MIXING ELEMENT. (A) METAL PIPES SANDWICHED BETWEEN TWO PLATES DIRECT SALT FLOW RADIALLY. (B) MILLED SLOTS IN TWO PLATES FORM CHANNELS THAT DIRECT THE SALT FLOW RADIALLY. (C) THICK TABBED WALL-COMPONENTS FORM CHANNELS THAT DIRECT SALT FLOW RADIALLY.

stead the design would have to be assembled and welded before transportation, making transportation more difficult and costly. Lastly, due to a change in the project's schedule, the mixing element needed to be manufactured in a week and transported the following weekend to the CSPonD system.

A potential way to deal with the bulkiness of the mixing element is to construct its three-dimensional structure from multiple, smaller two-dimensional components as done in origami. In particular, a design made from small sheet metal components can be manufactured cheaply and easily. Further, if stacks of these smaller components weight less than $23 \mathrm{~kg}$ apiece, the mixing element can he transported promptly as airline checked baggage. However, an issue with constructing the mixing element from multiple components is that every component needs to be secured. To avoid using a large number of fasteners, the smaller sheet metal components will also need to be interlocking or selffastening.

Overall, the ideal mixing element will have the following characteristics:

- Contain radial pathways such that its axial motion within the

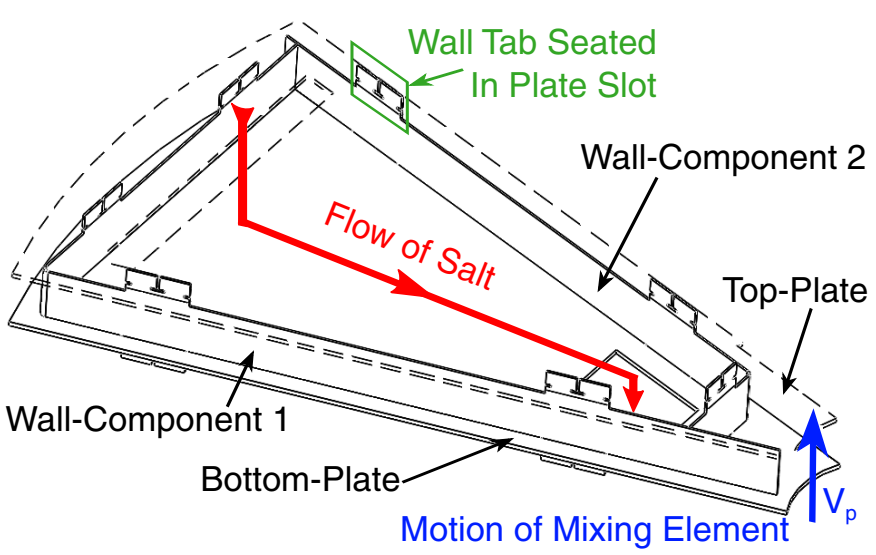

FIGURE 4: RADIAL CHANNEL FORMED FROM TABBED WALL-COMPONENTS WHICH SEAT INTO SLOTS IN THE TOP-AND BOTTOM-PLATES OF THE MIXING ELEMENT.

tank induces both axial and radial mixing of the solar salt;

- Majority of the solar salt flows through the mixing element, not around it;

- Have enough overall weight such that its downward velocity is on the same scale as its upward velocity;

- Be manufactured from multiple, smaller components that can be cheaply, easily, and quickly transported as airline checked baggage to the CSPonD system;

- Manufacture the smaller components from sheet metal to reduce the cost and increase the speed of manufacturing (reduce manufacturing time to under a week);

- Have the smaller components interlock or self-fasten like in origami to allow for easier assembly and reduce the number of fasteners needed.

\section{TAB AND SLOT CHANNELS}

For the mixing element's axial motion to induce radial flow and thus radial mixing of the salt, radial pathways are needed within the mixing element. These pathways consist of holes in the top and bottom of the mixing element that connect to radial channels within. Each channel is constructed from wallcomponents whose tabs seat into slots in the mixing element's top-and bottom-plates as shown in Figure 4. This does not produce a fluid-tight channel but is acceptable as the mixing element is submerged in the salt. Further, two bent wall-components are used to create all four sides of the channel as opposed to four wall-components. This is done to reduce the number of overall components and to increase the rigidity of the mixing element.

Overall, the mixing element has twelve channels constructed using this slot-and-tab technique. The holes for the channels alternate being near the center or edge of the mixing element on the top-and bottom-plates to ensure all the salt displaced by the 


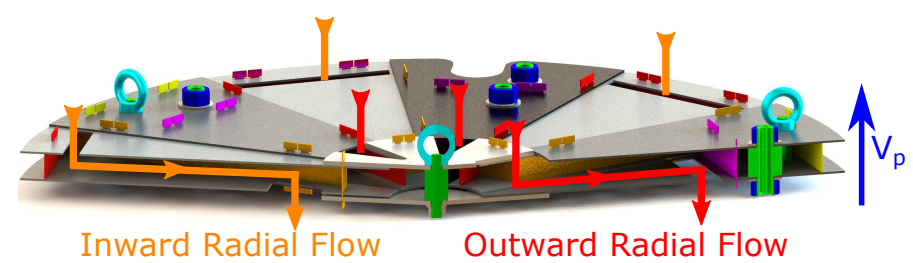

FIGURE 5: CROSS-SECTIONAL VIEW OF THERMAL MIXING ELEMENT SHOWING CROSS-FLOW BETWEEN ADJECENT CHANNELS TO PROMOTE RADIAL MIXING.

motion of the mixing element flows both inward and outward radially as shown in Figure 5 instead of in just one direction. This radial cross-flow ensures the heated salt in the center of the tank is not redistributed to the edges of the tank, but instead across the entire diameter of the tank. Further, the cross-flow also causes energy absorbed by the mixing element while near the top of the tank to evenly redistribute to salt moving toward both the edges and the center of the tank.

\section{CHANNEL FLOW}

Since radial mixing only occurs from salt flowing through the mixing element, not around it, majority of the salt needs to flow through the mixing element. The amount of salt that flows through the channels and the annulus is equal to the amount of salt displaced by the motion of the mixing element:

$$
\dot{V}_{\mathrm{p}}=N \dot{V}_{\mathrm{c}}+\dot{V}_{\mathrm{a}}
$$

where $N$ is the number of channels and $\dot{V}_{\mathrm{p}}, \dot{V}_{\mathrm{c}}$, and, $\dot{V}_{\mathrm{a}}$ are the total volumetric flow rate of the salt displaced by the mixing element's motion, the volumetric flow rate of the salt through each channel, and the volumetric flow rate of the salt through the annulus, respectively. The total volumetric flow rate caused by the mixing element's motion is

$$
\dot{V}_{\mathrm{p}}=A_{\mathrm{p}} v_{\mathrm{p}}
$$

where $A_{\mathrm{p}}$ is the cross-sectional area of the mixing element and $v_{\mathrm{p}}$ is the velocity of the mixing element.

As salt flows through each channel, a pressure drop $\Delta p_{\mathrm{c}}$ occurs over the channel as the channel resists the flow of salt along its length and forces the salt to change directions $90^{\circ}$ at its inlet and outlet:

$$
\Delta p_{\mathrm{c}}=\left(R_{\mathrm{c}}+2 R_{\text {elbow }}\right) \dot{V}_{\mathrm{c}}^{2}
$$

where $R_{\mathrm{c}}$ is channel's fluidic resistance along its length and $R_{\text {elbow }}$ is the channel's fluidic resistance from the $90^{\circ}$ elbows at the inlet and outlet. The channel's resistance along its length is

$$
R_{\mathrm{c}}=\frac{8 f_{\mathrm{c}} L_{\mathrm{c}} \rho_{\mathrm{salt}}}{\pi^{2} D_{\mathrm{c}}{ }^{5}}
$$

and the channel's inlet/outlet resistance is

$$
R_{\text {elbow }}=\frac{8 K_{\text {elbow }} \rho_{\text {salt }}}{\pi^{2} D_{\mathrm{c}}{ }^{4}}
$$

where $\rho_{\text {salt }}$ is the density of the solar salt, $f_{\mathrm{c}}$ is the friction factor of the channel, $L_{\mathrm{c}}$ is the length of the channel, $D_{\mathrm{c}}$ is the average hydraulic diameter of the channel, and $K_{\text {elbow }}$ is the loss coefficient for flow through a $90^{\circ}$ elbow.

The average hydraulic diameter of the channel is the average of the channel's hydraulic diameters at its inlet and outlet. The hydraulic diameter $D_{\mathrm{h}}$ of a cross-section is given by

$$
D_{\mathrm{h}}=\frac{4 A_{\mathrm{cs}}}{P_{\mathrm{cs}}}
$$

where $A_{\mathrm{cs}}$ is the area and $P_{\mathrm{cs}}$ is the perimeter of that cross-section. The elbow loss coefficient is dependent on the size of the channel as found on page 291 of [12], while the friction factor is dependent on the salt's Reynold's Number Re [13], generally given by

$$
R e=\frac{\rho \dot{V} D_{\mathrm{h}}}{\mu A_{\mathrm{cs}}},
$$

where $\rho, \mu$, and $\dot{V}$ are the density, viscosity, and volumetric flow rate of a fluid, respectively.

This pressure drop across each channel is equal to the pressure drop $\Delta p_{\mathrm{a}}$ across the annulus from salt flowing through it:

$$
\Delta p_{\mathrm{a}}=R_{\mathrm{a}} \dot{V}_{\mathrm{a}}^{2}
$$

where $R_{\mathrm{a}}$ is the annulus's fluidic resistance given by

$$
R_{\mathrm{a}}=\frac{8 f_{\mathrm{a}} L_{\mathrm{a}} \rho_{\text {salt }}}{\pi^{2} D_{\mathrm{a}}{ }^{5}}
$$

where $f_{\mathrm{a}}, L_{\mathrm{a}}$, and $D_{\mathrm{a}}$ are the friction factor, length, and hydraulic diameter of the annulus, respectively.

Setting Eqns. (3) and (8) equal and substituting the result into Eqn. (1), the volumetric flow rate through each channel is

$$
\dot{V}_{\mathrm{c}}=\left(N+\sqrt{\left(R_{\mathrm{c}}+2 R_{\text {elbow }}\right) / R_{\mathrm{a}}}\right)^{-1} \dot{V}_{\mathrm{p}}
$$




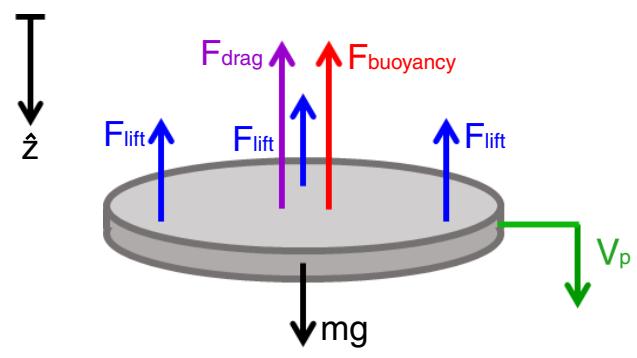

FIGURE 6: FORCES ACTING ON MIXING ELEMENT AS IT TRAVERSES UP AND DOWN THE TANK.

and the ratio of the flow through the channels to the total flow caused by the motion of the mixing element is

$$
\frac{N \dot{V}_{\mathrm{c}}}{\dot{V}_{\mathrm{p}}}=\frac{N}{N+\sqrt{\left(R_{\mathrm{c}}+2 R_{\text {elbow }}\right) / R_{\mathrm{a}}}}
$$

Thus to increase the proportion of flow going through the channels, the number of channels or the fluidic resistance of the annulus can be increased while the fluidic resistance of the channels can be decreased. The number of channels is coupled to the size of the channels and in turn the channel resistance though. Changing the annulus resistance on the other hand can be easily done by changing the diameter of the mixing element. However, as the mixing element's diameter approaches the tank's diameter, drag forces quickly increase on the mixing element as the mixing element within the tank begins to resemble a piston within a cylinder.

The forces acting on the mixing element during motion are shown in Figure 6. At steady state, these forces are

$$
\Sigma F=0=-3 F_{\text {lift }}-F_{\text {buoyancy }}-F_{\text {drag }}+m g,
$$

where $m$ is the mass of the mixing element. The lifting force applied $F_{\text {lift }}$ to the mixing element is

$$
F_{\text {lift }}= \begin{cases}F_{\text {winch }}, & v_{\mathrm{p}}=\text { negative }(\text { upward }) \\ 0, & v_{\mathrm{p}}=\text { positive }(\text { downward })\end{cases}
$$

where $F_{\text {winch }}$ is the line load each winch applies at the mixing element's steady state velocity according to the winch's torquespeed curve. When the mixing element moves downward, the winches apply a torque to overcome their breaks, but cannot apply a downward force as the chains connecting the mixing element to the winches cannot support compressive loads. The upward buoyancy force acting on the mixing element $F_{\text {buoyancy }}$ is

$$
F_{\text {buoyancy }}=\left(\rho_{\text {salt }} / \rho_{\mathrm{ss}}\right) m g
$$

where $\rho_{\mathrm{ss}}$ is the density of 304 stainless steel, which the mixing element is comprised of. Lastly, the drag force $F_{\text {drag }}$ acting on the mixing element is

$$
F_{\text {drag }}=\operatorname{sign}\left(v_{\mathrm{p}}\right) \Delta p A_{\mathrm{p}}
$$

where $\Delta p$ is the pressure drop across the channels and the annulus.

As the resistance of the annulus increases, a higher proportion of the salt will flow through the channels as desired. Since the resistance of the channels remains the same, the pressure drop across the mixing element will increase as shown by Eqn. (3) and in turn the drag force, as given by Eqn. (15). This is undesirable as according to Eqn. (12), the drag force will limit the upward and downward velocity of the mixing element. Thus the following trade-off exists. Increasing the annulus's fluidic resistance increases the portion of displaced salt flowing through the channels, but also deceases the mixing element's max velocity.

The number of channels, the channel sizes, and the diameter of the mixing element are chosen such that roughly $75 \%$ of the salt displaced by the motion of the mixing element is predicted to flow through the mixing element's channels. This allows the mixing element to move downward with a predicted velocity of $20 \mathrm{~mm} / \mathrm{s}$, a velocity on the same scale of its predicted upward velocity of $70 \mathrm{~mm} / \mathrm{s}$. Given the tank is $1.85 \mathrm{~m}$ tall, the mixing element is predicted to traverse from the bottom of the tank to the top of the tank and back in roughly two minutes, much faster than the predicted 50 minutes the insulating element is predicted to take to traverse from the top of the tank to the bottom of the tank when increasing the amount of stored energy.

\section{MODULAR DESIGN}

Overall, the mixing element is $1.23 \mathrm{~m}$ in diameter and 0.05 $\mathrm{m}$ thick with a total mass of $90 \mathrm{~kg}$. Majority of that mass comes from the top-and bottom-plates of the mixing element, which are $1.23 \mathrm{~m}$ in diameter and $3.2 \mathrm{~mm}(0.125 \mathrm{in})$ thick, each with a mass of $34 \mathrm{~kg}$. As a result, the mixing element is bulky and heavy, properties undesirable for transportation. To make the mixing element easier to transport, the top-and bottom-plates are each cut into twelve triangular-panels, one top-and one bottom-panel corresponding to each channel, and an additional center-panel. Each triangular-panel has a footprint of $0.46 \mathrm{~m} \times 0.35 \mathrm{~m} \times 3.2$ $\mathrm{mm}$ thick with an average mass of $2.7 \mathrm{~kg}$, while each centerpanel is $0.34 \mathrm{~m}$ in diameter $\times 6.35 \mathrm{~mm}(0.25$ in) thick with an average mass of $4.4 \mathrm{~kg}$, sizes and weights much easier to handle for transportation. In particular, this allows the mixing element to be transported from its manufacturing site in the USA to the CSPonD system in the UAE as five pieces of airline checked baggage, each under the airline baggage weight limit of $23 \mathrm{~kg}$, drastically reducing the cost of transportation. 

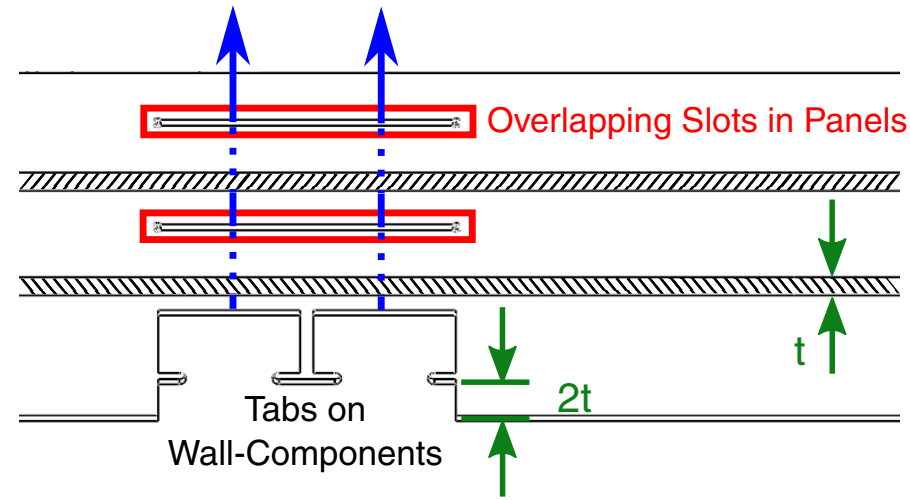

Primary Tab

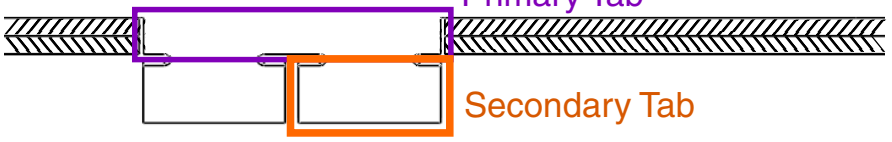

FIGURE 7: CROSS-SECTIONAL VIEW OF CHANNEL WALL-COMPONENTS' TABS ALIGNED WITH OVERLAPPING SLOTS IN TOP AND BOTTOM PLATES' PANELS.

For the panels to form the top-and bottom-plates, each panel is designed to overlap with its adjacent panels. Within this overlapping area, each panel also has a set of slots that overlap with slots on its adjacent panel as shown in Figure 7. The tabs of the channel wall-components are then inserted through both overlapping slots. In order for the tabs to insert into both panels, the height of each primary tab is twice the thickness of the panels. This allows the panels to interlock together to form the top-and bottom-plates of the mixing element as it is constructed. Figure 8 depicts how the panels and wall-components interlock to form the top-and bottom-plates of the mixing elements as well as the channels inside of it.

\section{BENT TAB FASTENERS}

Once the mixing element is constructed from inserting the wall-components' tabs into the top-and bottom-plates' panels, the entire structure needs to be fastened together. Given the mixing element has over 26 panels to construct the top-and bottomplates and an additional 21 wall-components to form the channels, a large number of fasteners is required. This is satisfied by using the wall-components' tabs as fasteners themselves. To use the tabs as fasteners, each tab is extended, notched and split into two smaller, secondary tabs which can be bent over as shown in Figures 9 and 10. The bent stabs secure the components as bending the tabs plastically deforms them, causing them to maintain their fastening shape even once the bending load is removed. The tabs are notched before spiting such that the tabs always bend in

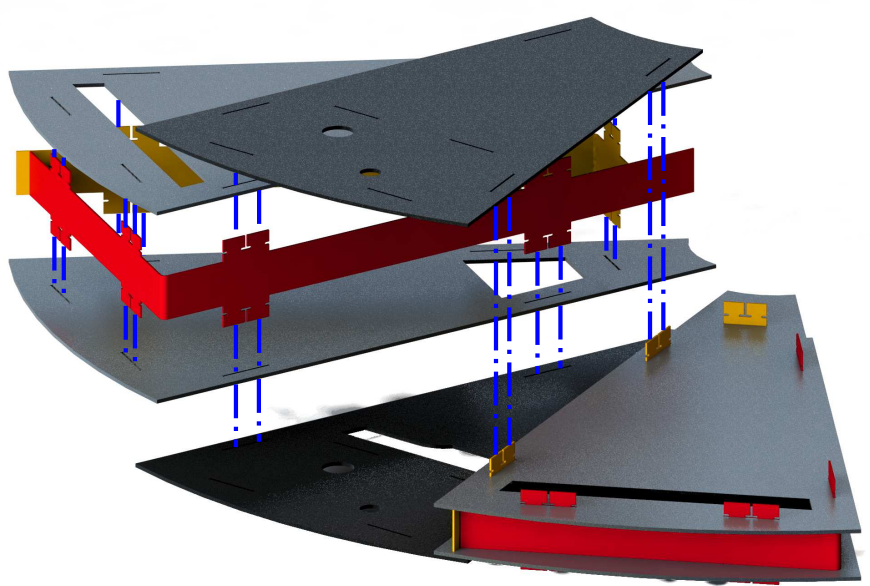

FIGURE 8: PARTIAL EXPLODED VIEW OF CHANNEL WALL-COMPONENTS' TABS INSERTED INTO TOP-AND BOTTOM-PLATES' PANELS.

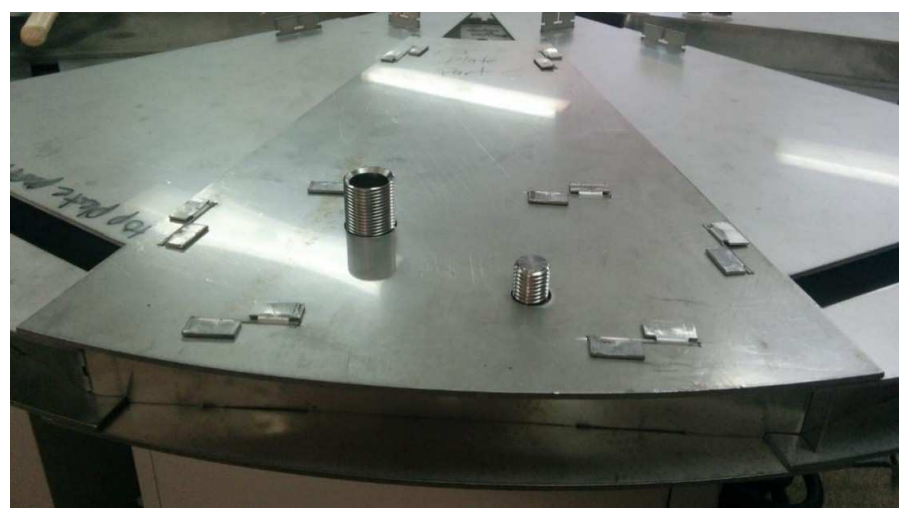

FIGURE 9: TABS BENT TO FASTEN THE MIXING ELEMENT'S TOP-AND BOTTOM-PANELS TO THE CHANNEL WALL-COMPONENTS.

the same location. Further, each tab splits into two smaller, secondary tabs, which are bent in opposite directions, so that loads applied to the tabs do not induce moments within the channel walls as shown in Figure 11.

The tabs are designed conservatively, such that they will not fracture under the worst loading conditions they could possibly experience. The worst loading configuration for the tabs is shown in Figure 12. To install the mixing element, the mixing element is lowered into the tank by an eye nut attached to a standoff running through the middle of the mixing element. This central standoff, in parallel with twelve tabs in the middle of the mixing element, carry the weight of the entire mixing element reduced by the buoyancy force of the salt. Since the standoff is much stiffer than the tabs, it carries majority of this load. If 


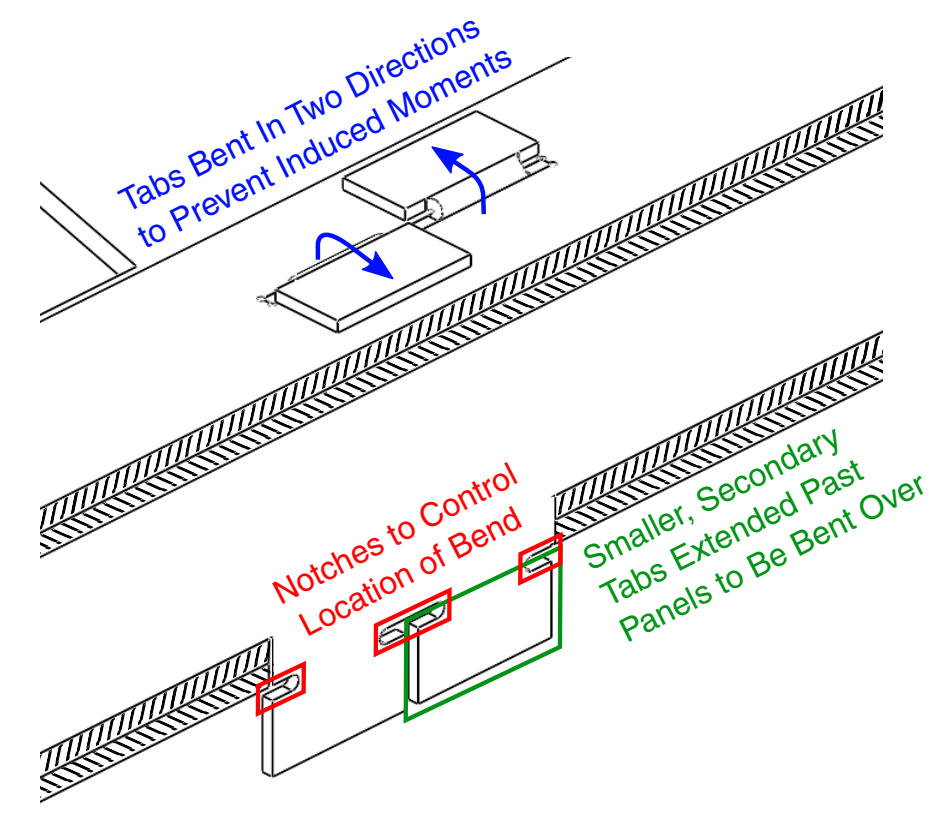

FIGURE 10: CROSS-SECTIONAL VIEW OF CHANNEL WALL-COMPONENTS' TABS BENT TO SECURE THE CHANNEL WALLS AND TOP/BOTTOM PANELS TOGETHER.

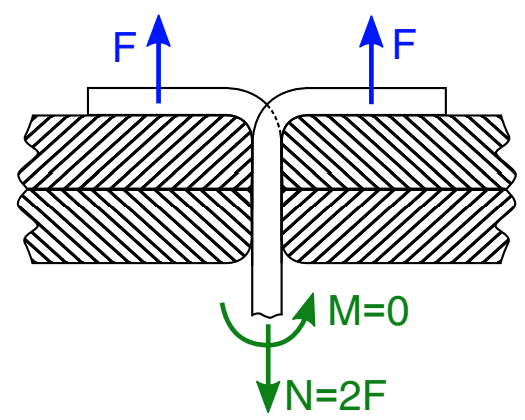

FIGURE 11: TABS BENT IN OPPOSITE DIRECTIONS PREVENTS FORMATION OF INTERNAL MOMENTS WITHIN THE CHANNEL WALLS WHEN LOADS ARE APPLIED.

this standoff becomes disconnected from the bottom of the mixing element, it will continue to connect the eye nut to the top of the mixing element, but will no longer carry any of the load. In such a case, the twelve tabs in the center experience their worst loading condition, which is carrying the entire weight of mixing element reduced by the buoyancy force of the salt.

To design the tabs against fracture, the maximum stress in the tabs is compared to the ultimate tensile stress of 304 stainless steel at $538^{\circ} \mathrm{C}$. The maximum stress within a tab will occur along the inner edge of the tab's bent section as shown in Figure 13. At

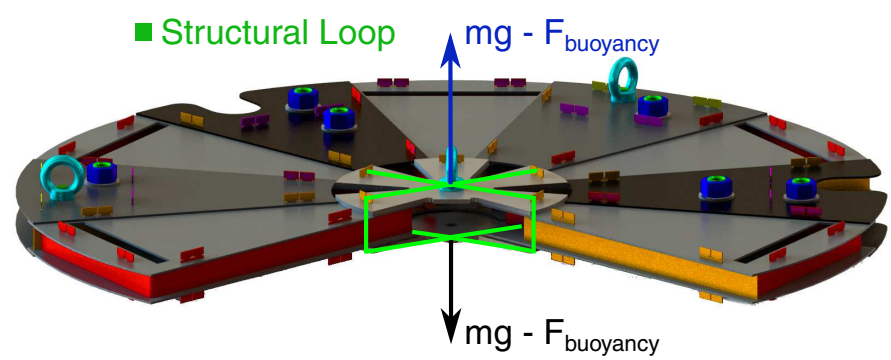

FIGURE 12: DURING INSTALLATION, IF THE MIXING ELEMENT'S CENTER LIFTING STANDOFF FAILS, 12 TABS IN THE CENTER MUST SUPPORT THE ENTIRE WEIGHT OF THE MIXING ELEMENT REDUCED BY THE BUOYANCY FORCE FROM THE SALT.

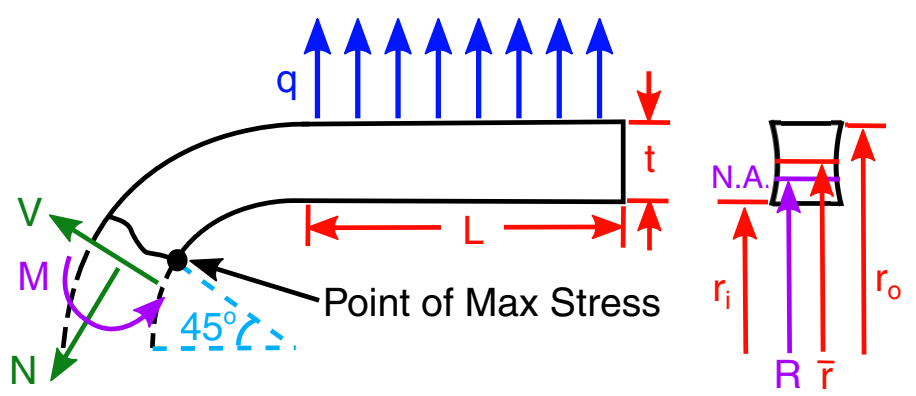

FIGURE 13: INTERNAL LOADS OF THE TAB AT THE POINT OF MAXIMUM TANGENTIAL STRESS.

this point, the highest stress $\sigma_{\mathrm{s}}$ in the tab is given by

$$
\sigma_{\mathrm{s}}=K_{\mathrm{t}} \frac{\mathcal{N}}{A_{\mathrm{R}}}+K_{\mathrm{b}} \frac{\mathcal{M}\left(R-r_{\mathrm{i}}\right)}{A_{\mathrm{R}}(\bar{r}-R) r_{\mathrm{i}}},
$$

where for the tab's bent region, $A_{\mathrm{R}}$ is the cross-sectional area, $\vec{r}$ is the radius of the centroidal axis, $r_{\mathrm{i}}$ and $r_{\mathrm{O}}$ are the inner and outer radii, $R$ is the radius of of the neutral axis, $\mathcal{N}$ and $\mathcal{N}$ are the internal normal force and moment, and $K_{\mathrm{t}}$ and $K_{\mathrm{b}}$ are the stress concentration factors due to the tab's notches under axial tension and transverse bending. These stress concentration factors are approximated from the stress concentration factors for a flat finite-width plate with opposite U-shaped notches on pages 274275 in [14]. Since the bent region has a rectangular cross-section with thickness $t$,

$$
\begin{gathered}
R=\frac{t}{\ln \left(r_{\mathrm{o}} / r_{\mathrm{i}}\right)}, \\
r_{\mathrm{i}}=\bar{r}-t / 2,
\end{gathered}
$$




$$
r_{\mathrm{o}}=\bar{r}+t / 2 .
$$

From force balance, the internal loads are

$$
\mathcal{N}=q L / \sqrt{2},
$$

and

$$
\mathcal{M}=q L(L / 2+\bar{r} / \sqrt{2}),
$$

where $q$ is the distributed load applied to each tab over its length $L$ due to the weight of the mixing element minus the salt's buoyancy force:

$$
q=\frac{m g-F_{\text {buoyancy }}}{12 \text { tabs } \cdot L} .
$$

Using Eqn. (16), the tabs are sized such that the max stress within the tab is $\sigma_{\mathrm{s}}=190 \mathrm{MPa}$. The ultimate tensile stress of 304 stainless steel at $538^{\circ} \mathrm{C}$ is $386 \mathrm{MPa}$ [15], resulting in a safety factor of 2.0. This is adequate as this worst loading condition only occurs when the central standoff detaches from the mixing element's bottom-plate. This is highly unlikely as the standoff is attached to the bottom-plate with a top-lock distorted-thread locknut, which will expand when heated by the salt, further keeping the joint from vibrating loose. To verify the maximum stress on the tabs, SolidWorks finite element analysis (FEA) is used. FEA found the maximum stress on the tabs to be $270 \mathrm{MPa}$ as shown in Figure 14. While this is higher than calculated, this is expected as stress concentration factors used are for a flat plate with notches, not a plate bent at $90^{\circ}$. This results in a safety factor of 1.4, which again is adequate as this worst loading condition is highly unlikely to occur.

\section{CONCLUSION}

The CSPonD system at Masdar Institute heats a tank of molten salt with sunlight, storing the sun's energy thermally and generating electricity when needed using a heat exchanger. Since incoming sunlight only heats the upper most layers of salt in the center of the tank, strong thermal gradients can form (decreasing the heat exchanger's efficiency) and the salt can overheat (and become corrosive). To reduce this thermal gradient and safeguard against the salt overheating, a mixing element with internal, radial channels, traverses up and down the hot region of salt. The

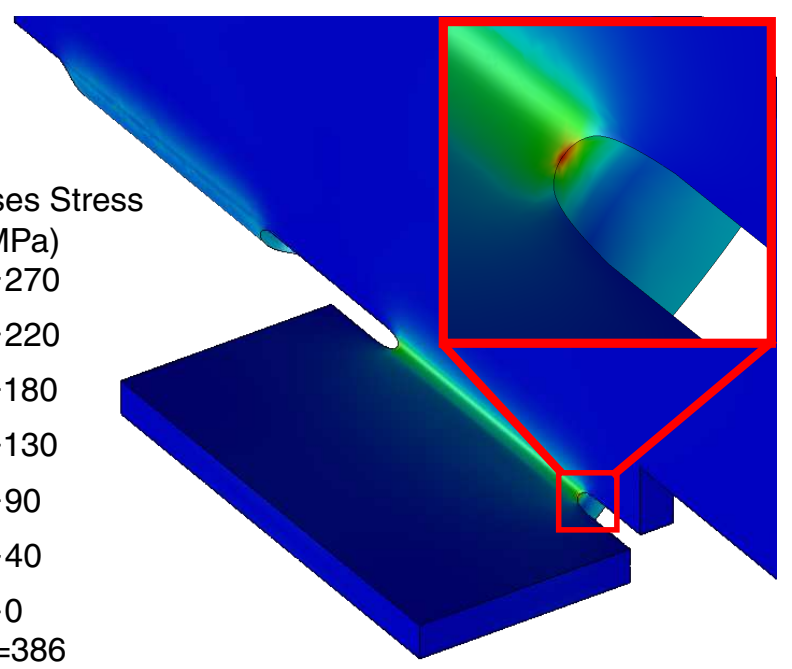

FIGURE 14: SIMULATION OF MAX STRESS IN THE TABS. UNDER THE WORST LOADING, THE TABS HAVE A SAFETY FACTOR OF 1.4.

salt displaced by this motion either flows axially around the mixing element, inducing only axially-mixing, or axially and radially through the mixing element, inducing both axial and radial mixing.

To promote radial mixing, the mixing element's diameter $(1.23 \mathrm{~m})$ is close to the diameter of the tank $(1.25 \mathrm{~m})$ such that the annulus around the mixing element has a higher fluidic resistance and thus lower flow rate than the channels through the mixing element. While these dimensions allow a predicted $75 \%$ of the salt to flow through the channels, they also increase the drag force on the mixing element. As a result, the mixing element has a mass of $90 \mathrm{~kg}$ in order to move downward at a predicted 20 $\mathrm{mm} / \mathrm{s}$, a velocity on the same scale of its predicted upward velocity of $70 \mathrm{~mm} / \mathrm{s}$. These velocities are adequate as the mixing element would be able to traverse up and down the entire tank in two minutes, every ten minutes, as compared to the insulating element's predicted 50 minutes to traverse from just the top of the tank to the bottom when charging the tank with solar energy.

Due to the large diameter and weight of the mixing element, initial, pre-origami inspired designs for the mixing element had several issues. First, they were slow and difficult to manufacture. For example, each design had large plates which would require a large machine to cut. Second, these designs would be difficult and costly to transport. Again, this would primarily be due to the large plates. Lastly, the designs would be slow and difficult to assemble due to the potentially large number of fasteners required. To mitigate these complications in order to manufacture the mixing element within a week and transport it the following weekend due to a change in the project's schedule, the three-dimensional structure of the mixing element was 
redesigned to be constructed from multiple, two-dimensional, interlocking components as done in origami.

In particular, the internal, radial channels within the mixing element were constructed from tabbed wall-components whose tabs seat into and extend past slots in the top-and bottom-plates of the mixing element. The top-and bottom-plates themselves were no longer single, large plates, but twelve $2.7 \mathrm{~kg}$ slotted, triangular-panels, one for each channel, and an additional 3.1 $\mathrm{kg}$ slotted, center-panel. During assembly, the slots of adjacent panels would overlap, allowing the panels to form the top-and bottom-plates when the wall-components' tabs were inserted. These components then fastened together by bending the overextending tabs. This allowed the mixing element to be fabricated quickly and cheaply from sheet metal, for it to be transported as five pieces of airline checked baggage, each under the airline baggage weight maximum of $23 \mathrm{~kg}$, and for it to be assembled with only a few fasteners.

To use bent tabs as fasteners the following steps were taken, which can be done again to use bent tabs as fasteners in the future. First, the tabs were split into two halves, which can be bent in opposite directions such that loads applied to the tabs do not induce internal moments. Second, each tab was notched, splitting them into primary and secondary parts and causing the tabs to bend consistently in the same location. Third, the primary section of the tab was as long as the sum of the thickness of the components to be fastened together. For the mixing element, this was the sum of the thickness of adjacent panels forming the top-and bottom-plates. Lastly, the tabs were conservatively sized such that their max stress was below the ultimate tensile stress of their material under their worst loading configuration. For the mixing element, this entailed having the max stress in the twelve center-tabs be below the ultimate tensile stress of 304 stainless steel at $538{ }^{\circ} \mathrm{C}(386 \mathrm{MPa})$ if those tabs had to carry the mixing element's entire weight reduced by the buoyancy force of salt. The max stress was calculated to be $190 \mathrm{MPa}$, providing a safety factor of 2, but FEA revealed the max stress to be higher at 270 $\mathrm{MPa}$, reducing the safety factor to 1.4 , as the stress concentration factors due to the notches could only be approximated in the calculations.

\section{ACKNOWLEDGMENT}

This work was perfomed in collaboration with and supported by the Masdar Institute of Institute of Science and Technology.

\section{REFERENCES}

[1] Turner, N., Goodwine, B., and Sen, M., 2016. "A review of origami applications in mechanical engineering". Proceedings of the Institution of Mechanical Engineers, Part C: Journal of Mechanical Engineering Science, 230(14), August, pp. 2345-2362.
[2] Upadhe, S., Chavan, A., and Shaikh, T., 2014. "Industrial origami a review". International Journal of Innovative Research in Advanced Engineering, 1(7), pp. 265-269.

[3] Construction techniques: $\mathrm{Tab}$ and slot with t-nut construction. Big Blue Saw. On the WWW, at http://www.bigbluesaw.com/articleslist/big-blue-saw-designing-forwaterjet/construction-techniques-taband-slot-with-t-nut-construction.html.

[4] Gaun, C., 2012. How to build your everything really really fast, December. On the WWW at http://www. instructables.com/id/How-toBuild-your-Everything-Really-ReallyFast/.

[5] Kelly, G., Klimko, R., Sieck, C., and Wetherill, R., 2000. Method for securing a first fabrication element to a second fabrication element during a welding operation, October. US Patent 6,131,286.

[6] Bishop, J. C., and Holme, M. J., 2004. Joint for sheet material and a method of joining sheet material, July. US Patent $6,761,502$.

[7] Roth, L., and Wybenga, G., 2000. The Packaging Designer's Book of Patterns. Wiley, Hoboken, NJ.

[8] Codd, D. S., 2011. "Concentrated solar power on demand". Phd thesis, Mechanical Engineering, Massachusetts Institute of Technology, Cambridge, MA.

[9] Slocum, A. H., Codd, D. S., Buongiorno, J., Forsberg, C., McKrell, T., Nave, J.-C., Papanicolas, C. N., Ghobeity, A., Noone, C. J., Passerini, S., Rojas, F., and Mitsos, A., 2011. "Concentrated solar power on demand". Solar Energy, 85(7), pp. 1519-1529.

[10] Gil, A., Codd, D. S., Zhou, L., Trumper, D., Campbell, R. B., Grange, B., Calvet, N., Armstrong, P., and Slocum, A. H., 2015. "Design of a $100 \mathrm{kw}$ concentrated solar power on demand volumetric receiver with integral thermal energy storage prototype". In ASME 2015 Power Conference, American Society of Mechanical Engineers, pp. 1-7.

[11] Steinfeld, A., and Schubnell, M., 1993. "Optimum aperture size and operating temperature of a solar cavity-receiver". Solar Energy, 50(1), pp. 19-25.

[12] White, F., 2011. Fluid Mechanics. McGraw-Hill series in mechanical engineering. McGraw Hill, New York, NY.

[13] Moody, L. F., 1944. "Friction factors for pipe flow". Trans. ASME, 66(8), pp. 671-684.

[14] Pilkey, W., 2005. Formulas for stress, strain, and structural matrices. Wiley, Hoboken, NJ.

[15] 304/304L stainless steel product data bulletin. AK Steel Corporation. On the WWW, at http: //www.aksteel.com/pdf/markets_products / stainless/austenitic/304_3041_data_ bulletin.pdf. 